\title{
EFFECT OF THE HERBICIDE PARAQUAT-GRAMOXONE (1, 1' DIMEHYL - 4, 4' - BIPIRIDILIUM DICHLORIDE) ON THE BEHAVIOR OF THE FISH \\ Centropomus parallelus
}

\author{
GONÇALVES, N.M.F.M. ${ }^{1}$; FOLLE, N.M.T. ${ }^{2}$; SEKITAMI, E.N.S. ${ }^{3}$; TRAMONTIN, L. ${ }^{3}$ \\ ${ }^{1}$ Pontifícia Universidade Católica do Paraná; \\ ${ }^{2}$ Faculdades Integradas Espíritas; \\ ${ }^{3}$ Graduandas do Curso de Nutrição, PUC-PR.
}

The abusive and indiscriminate use of pesticides in economically important culture areas has been causing serious problems for the ecosystem and the human health due to their poisonous effects. Also, by poluting the water, they contaminate the aquatic organisms. The main aim of the present research is to study the behavior of the seawater fish, Centropomus parallelus under the effect of sublethal concentrations of the herbicide Paraquat-Gramoxone, 1,1' dimethyl - 4,4' - bipiridinium dichloride. The following parameters were studied: the determination of the bioacumulation factor under the fish exposition towards this herbicide, during a period of 21 days of experiment; the assay of Paraquat residues by gas chromatography and spectrophotometry in fish muscle and in the aquarium water in elapsing periods of 76 hours from the beginning of the experiment; hystopathological study of the possible effects caused by Paraquat in different trissues and organs of the experimental fish by optic and electronic microscopy. Parameters of fish behavior under the effect of Paraquat were assayed in regard to the feeding evaluation, feces, breathing, mobility, rest, aggressiveness and color of the body. The behavioral observations were accomplished in elapsing periods of 7 days, being the time of observation of $10 \mathrm{~min} / \mathrm{h}$ each 10 hours. The experiments were carried out with pilot groups of 12 animals, at the Center of Production and Propagation of Sea Animals, Guaratuba, Pontifícia Universidade Católica do Paraná and the Laboratory of Biochemistry, Department of Medicine, Pontifícia Universidade Católica do Paraná. Gas chromatography and electronic microscopy experiments were carried out at the Federal University of Paraná.

Key Words: herbicide, Paraquat, fish. 